\title{
INFLUENCE OF RAMADAN ON NEUROPERFORMANCE IN HEALTHY WORKERS
}

\author{
Mertens $\mathrm{A}^{\mathrm{a}}$, Schouteden $\mathrm{M}^{\mathrm{a}}$, Godderis $\mathrm{L}^{\mathrm{ab}}$. \\ ${ }^{a}$ IDEWE, External Service for Prevention and Protection at work, Interleuvenlaan 58, 3001 \\ Heverlee, Belgium. \\ ${ }^{\mathrm{b}}$ Katholieke Universiteit Leuven, Centre for Environment \& Health, Kapucijnenvoer 35/5, \\ 3000 Leuven, Belgium.
}

\begin{abstract}
Background - During Ramadan, Muslims refrain from eating and drinking from dawn until sunset. In 2012, Ramadan took place during summer, with fasting periods up to 19 hours. Previous studies have reported delays in sleeping and waking time and consequently decreased daytime alertness. Nevertheless, data on the effects of Ramadan on neuroperformance are scarce.
\end{abstract}

Aims - We investigated the impact of Ramadan on tiredness and neuroperformance in Belgian Muslims.

Methods - 20 Subjects were tested outside of Ramadan, halfway through Ramadan and in the last week of Ramadan. Tiredness was assessed with the Fatigue Assessment Scale (FAS) and alertness with the Stanford Sleepiness Scale (SSS).

Neuroperformance was tested with the simple reaction time for reaction time (REA-t) and concentration (REA-sd), symbol digit substitution for visual perception (SDS), digit span backwards for short term memory (DSB) and hand-eye coordination test (EYE).

Results - Ramadan had no effect on FAS. SSS increased during Ramadan, but remained within normal physiological boundaries. There was no significant effect on REA-t and SDS. Ramadan had beneficiary effects on REA-sd, DSB and EYE. There were no correlations between FAS or SSS and other neuroperformance parameters.

Conclusion - Daytime sleepiness moderately increases during Ramadan. Neuroperformance remains mostly unaffected. Concentration improved during Ramadan, but we observed are large interindividual differences.

Keywords: ramadan; fasting; cognitive function; vigilance; sleepiness 


\section{INTRODUCTION}

During Ramadan, Muslims refrain from eating and drinking from dawn till sunset. In 2012, Ramadan started July 20th and finished August 18th. In Europe, this implied fasting periods of about nineteen hours at the beginning of Ramadan to around sixteen hours at the end.

Many studies report changes in circadian rhythms during Ramadan, with general delay in both bedtime and waking up hour (Ziaee et al 2006, BaHammam 2005, BaHammam 2006). In Islamic countries, daytime activities and working hours are often adapted to the changed rhythm during Ramadan (BaHammam et al 2010, Roky et al 2001). Many studies suggest a decreased daytime alertness during Ramadan in Islamic countries (BaHammam 2006, Roky et al 2000). The question arises whether this is also the case in western countries where working hours remain unchanged.

European employers have expressed concerns about the alertness of Muslim employees while performing potentially dangerous activities or keep concentrated during mentally straining tasks.

Most studies assessing alertness or sleepiness by questionnaires during Ramadan measured an increased subjective perception of sleepiness during daytime (Roky et al 2000, Zerguini et al 2008). Objective sleepiness measured by EEG seems slightly increased between 10:00 and 12:00 h. At other times of the day there were no important differences with results outside the Ramadan (Roky et al 2003).

Previous studies did not provide an answer to whether increased subjective sleepiness leads to a diminishment of neuroperformance. Data on neuroperformance parameters is scarce and results are contradictory. Two studies found a slower reaction speed during the first week of Ramadan (Roky et al 2004, Dolu et al 2007), while measurements in the second half of Ramadan showed no effect on reaction speed (Roky et al 2000, Tian et al 2011). Information processing speed and concentration were decreased in the first week of Ramadan in one study (Roky et al 2004), but were better than normal in another study (Lotfi et al 2010). Short time memory was better during Ramadan in one study (Lotfi et al 2010), while unaffected in another. (Tian et al 2011).

The aim of this study was to assess the impact of Ramadan on subjective sleepiness and neuroperformance in a nonIslamic Western country.

\section{METHODS AND SUBJECTS}

Volunteers were recruited via posting messages near mosques and on Islamic forums in Belgium. The study was approved by the Medical Ethics of the Catholic University of Leuven (reference number: S54398). Participants were informed of the objectives of the study and the confidentiality of their results in accordance to the declaration of Helsinki. Finally, 20 healthy subjects agreed to participate in an observational study including three test sessions.

Reference test sessions took place a week before Ramadan or a month after Ramadan, depending on the availability of the participant. During Ramadan, two sessions took place: the first one halfway (R1) and the second one in the last week of Ramadan (R2). Timing of the sessions varied between 12:30h and 20:30h. Each individual participant was always tested around the same time of day.

Subjects filled out a questionnaire about sleeping and eating habits. Dutch 
versions of the Fatigue Assessment Scale (FAS) (Michielsen et al 2004) and the Stanford Sleepiness Scale (SSS) (Hoddes et al 1973) were used to measure the subjective perception of respectively global fatigue in the past week and sleepiness at the time of the test. The FAS is a 10-item questionnaire in which each statement is scored between 1 (never) and 5 (always). Total FAS score varies between 10 and 50. FAS scores of 21 or higher indicate excessive fatigue (Michielsen et al 2004). The SSS is a 7point Likert scale ranging between "Feeling active, vital, alert or wide awake" to "No longer fighting sleep, sleep onset soon and having dream-like thoughts". SSS scores may vary throughout the day between 1 and 3, which are considered normal physiological fluctuations. Scores of 4 and higher indicate sleep shortage and excessive sleepiness (Hoddes et al 1973).

Neuroperformance was assessed with four neurobehavioral tests of the computer assisted Neuroscreen test battery (Bultereys and Viaene 1994, Godderis et al 2010). Simple Reaction Time measured reaction speed (REA-t: average reaction time out of 60 measurements presented at random in intervals) and attention (REAsd: standard deviation around the average time). Visual information processing speed was evaluated using Symbol Digit Substitution (SDS), in which subjects need to link digits to symbols as fast as possible. Five trials are given. Mean performance out of 4 trials was recorded (omitting the first trial). Digit Span Backwards (DSB) test was used to evaluate short time memory. The mean number of digits was calculated from 20 consecutive trials in which the number of digits is going up or down with one digit depending on whether the test person entered the answer correctly or not. For DSB, higher scores are better scores. Hand Eye Coordination (EYE) was assessed by asking the subjects to guide a cursor along a curve using a joystick (seven trials and two test trials). The given value for this test is the number of pixels between this curve and the actual trajectory of the cursor and is an indicator of visuomotor performance. For the EYE test, lower values are better.

For the statistical analysis, continuous data were summarized by descriptive statistics (mean and standard deviation). Changes over time of each dependent variable were analysed using multilevel analysis, which is especially suited to analyse repeated- measure data because it takes into account the dependencies among observations nested within individuals. Another advantage of this method (versus e.g. repeated measurement ANOVA) is its ability to handle missing data. Random coefficient models were fitted for all dependent variables, allowing for individual variation in intercept and regression slopes of the time-varying predictors. Two time-varying predictors were included in the model, being time of measurement (Time) and whether or not the measurement was taken during Ramadan (Ramadan). (In all models, Time was included as a variable with values $0,1,2,3$ while Ramadan was included as a dummy variable with $0=$ measurement taken before and after Ramadan and $1=$ measurement taken during Ramadan). Fixed and random effects of Time and Ramadan were tested using $\chi^{2}$ tests. All models were fitted using $R$ version 2.15 .1 with $R$-package nmle version 3.1-104. Before analysis, data were examined for normality. In case of nonnormal distributed data, a suitable datatransformation was applied (e.g. logtransformation on positively skewed data). One-Way ANOVA was used for checking correlations, using statistical package software SPSS 20. 


\section{RESULTS}

10 men and 10 women aged 31.6 (SD \pm 6.4 ) participated in this study. All subjects where tested at both sessions during Ramadan. 11 participants had one reference test before Ramadan and 4 participants had one reference session after Ramadan. 5 participants were present at both reference sessions and were tested four times in total. 15 subjects had a bachelor or master diploma. The other 5 participants had a high school diploma. 4 of the lower educated subjects and 2 of the higher educated subject had a job that could be classified as physically straining. 9 participants had at least one hour of sports training weekly. 2 participants had a completely sedentary lifestyle with less than 30 minutes of moderate exercise a day. None of the participants were smokers.

An overview of mean scores and standard deviations for FAS, SSS, REA-sd, SDS, DSB, and EYE for the four test sessions are shown in table 1 . The results of the multilevel analysis are given in table 2 and visually illustrated in figure 1.

\subsection{Fatigue Assessment Scale}

During Ramadan, mean bedtime was 90 minutes later than normal. In the first half of Ramadan (R1) waking up was 73 minutes later than normal and by the end of Ramadan (R2) 136 minutes later. Average sleep was unchanged in $\mathrm{R} 1$ but was on average 32 minutes less in $\mathrm{R} 2$. Seven subjects had a FAS score of 21 or higher during reference measurements, eight subjects scored high at R1 and seven subjects at R2. Average FAS was 20.28 outside Ramadan, 20.05 in R1 and 20.65 in R2. Multilevel analysis revealed nonsignificant effects of Ramadan or Time on FAS $\left(\chi^{2}(2)=0.15 ; \mathrm{NS}\right)$.

Table 1. Effects of Time and of Ramadan on Fatigue and NeuroscreenResults

\begin{tabular}{lccccccc}
\hline & SSS & FAS & $\begin{array}{c}\text { REA-t } \\
(\mathrm{ms})\end{array}$ & $\begin{array}{c}\text { REA-sd } \\
(\mathrm{ms})\end{array}$ & $\begin{array}{c}\text { SDS } \\
(\mathrm{s})\end{array}$ & $\begin{array}{c}\text { DSB } \\
(\text { digits })\end{array}$ & $\begin{array}{c}\text { EYE } \\
(\mathrm{pxls})\end{array}$ \\
\hline $\begin{array}{l}\text { Before } \\
\begin{array}{l}\text { Ramadan } \\
(\mathrm{n}=16)\end{array}\end{array}$ & $2.25 \pm 0.8$ & $20.81 \pm 4.4$ & $278 \pm 62$ & $66 \pm 36$ & $14.6 \pm 3.8$ & $6.2 \pm 1.3$ & $2382 \pm 1178$ \\
\hline $\begin{array}{l}\text { Halfway } \\
\text { Ramadan } \\
(\mathrm{n}=20)\end{array}$ & $2.50 \pm 1.0$ & $20.05 \pm 6.0$ & $265 \pm 30$ & $50 \pm 15$ & $13.5 \pm 4.6$ & $6.9 \pm 2.1$ & $1989 \pm 795$ \\
\hline $\begin{array}{l}\text { Last Week } \\
\text { Ramadan } \\
(\mathrm{n}=20)\end{array}$ & $2.72 \pm 1.3$ & $20.65 \pm 6.0$ & $263 \pm 22$ & $51 \pm 17$ & $12.7 \pm 3.6$ & $7.3 \pm 1.6$ & $1735 \pm 540$ \\
\hline $\begin{array}{l}\text { After } \\
\text { Ramadan } \\
(\mathrm{n}=9)\end{array}$ & $1.78 \pm 0.6$ & $19.33 \pm 5.1$ & $276 \pm 37$ & $68 \pm 22$ & $10.9 \pm 3.4$ & $7.8 \pm 1.5$ & $1569 \pm 631$ \\
\hline
\end{tabular}

SSS stanford sleepiness scale; FAS fatigue assessent scale; REA-T reaction time; REA-SD concentration; SDS symbol digit substitution; DSB digit span backward; EYE eye hand coördination

Values are given as means \pm standard deviation 
Table 2. Results of the multilevel analysis for the different (log-transformed) dependent variables.

\begin{tabular}{|c|c|c|c|c|c|c|c|}
\hline & SSS & FAS & $\begin{array}{c}\log 10 \\
(\text { REA-T) }\end{array}$ & $\begin{array}{c}\log 10 \\
(\mathrm{REA}-\mathrm{SD})\end{array}$ & SDS & DSB & $\begin{array}{l}\text { Log10 } \\
\text { (EYE) }\end{array}$ \\
\hline \multicolumn{8}{|l|}{ fixed effect } \\
\hline intercept & $\begin{array}{c}2.10 \\
(0.17) * * *\end{array}$ & $\begin{array}{c}20.26 \\
(1.01)^{* * *}\end{array}$ & $\begin{array}{c}2.42 \\
(0.01)^{* * *}\end{array}$ & $\begin{array}{c}1.78 \\
(0.03)^{* * *}\end{array}$ & $\begin{array}{c}2.23 \\
(0.13)^{* * *}\end{array}$ & $\begin{array}{c}5.78 \\
(0.44)^{* * *}\end{array}$ & $\begin{array}{c}3.55 \\
(0.05)^{* * *}\end{array}$ \\
\hline time & $(0.11)$ & (1.01) & (0.01) & (0.00) & $\begin{array}{c}-0.12 \\
(0.02)^{* * *}\end{array}$ & $\begin{array}{c}0.42 \\
(0.13)^{* * *}\end{array}$ & $\begin{array}{c}-0.06 \\
(0.01)^{* * *}\end{array}$ \\
\hline ramadan & $\begin{array}{c}0.50 \\
(0.25)^{* *}\end{array}$ & - & - & $\begin{array}{c}-0.10 \\
(0.04)^{* * *}\end{array}$ & $x^{2}$ & $\begin{array}{c}0.43 \\
(0.24)^{*}\end{array}$ & $\begin{array}{c}-0.05 \\
(0.02)^{* *}\end{array}$ \\
\hline \multicolumn{8}{|l|}{$\begin{array}{l}\text { Variances }+95 \% \\
\text { CI }\end{array}$} \\
\hline intercept & $\begin{array}{c}0.35 \\
(0.08-1.55)\end{array}$ & $\begin{array}{c}3.97 \\
(2.66-5.92)\end{array}$ & $\begin{array}{c}0.03 \\
(0.02-0.05)\end{array}$ & $\begin{array}{c}0.08 \\
(0.04-0.15)\end{array}$ & $\begin{array}{c}0.52 \\
(0.37-0.71)\end{array}$ & $\begin{array}{c}1.36 \\
(0.95-1.93)\end{array}$ & $\begin{array}{c}0.15 \\
(0.11-0.22)\end{array}$ \\
\hline slope time & - & - & - & - & - & - & - \\
\hline slope ramadan & $\begin{array}{c}0.73 \\
(0.32-1.64)\end{array}$ & - & - & - & - & - & - \\
\hline corr & $\begin{array}{c}0.36 \\
(-0.98-0.99)\end{array}$ & - & - & - & - & - & - \\
\hline residual & $\begin{array}{c}0.73 \\
(0.56-0.95)\end{array}$ & $\begin{array}{c}3.77 \\
(3.07-4.64)\end{array}$ & $\begin{array}{c}0.04 \\
(0.03-0.04)\end{array}$ & $\begin{array}{c}0.14 \\
(0.11-0.17)\end{array}$ & $\begin{array}{c}0.15 \\
(0.13-0.19)\end{array}$ & $\begin{array}{c}0.89 \\
(0.73-1.10)\end{array}$ & $\begin{array}{c}0.09 \\
(0.07-0.11)\end{array}$ \\
\hline icc & 0.33 & 0.52 & 0.45 & 0.19 & 0.87 & 0.61 & 0.61 \\
\hline \multicolumn{8}{|l|}{ Fit-statistics } \\
\hline PRV & 0.31 & - & - & 0.14 & 0.43 & 0.29 & 0.50 \\
\hline pseudo-R2 & 0.71 & 0.67 & 0.62 & 0.47 & 0.95 & 0.47 & 0.86 \\
\hline
\end{tabular}

SSS stanford sleepiness scale; FAS fatigue assessment scale; REA-T reaction time; REA-SD concentration; SDS symbol digit substitution; DSB digit span backward; EYE eye hand coordination

Values are given as means (standard deviation), and numbers (95\% CI)

* $P<0.10$;** $P<0.05 ; * * * P<0.01$; - indicated a non-significant effect

\section{2. $\quad$ Stanford Sleepiness Scale}

The average SSS was 2.00 outside Ramadan, 2.50 in R1 and 2.72 in R2. One subject scored 4 on SSS during reference measurements. Three subjects scored 4 or higher at R1 and seven subjects scored 4 or higher at R2. Multilevel analysis revealed a small effect of Ramadan: for an average person, SSS increased with 0.50 points during Ramadan $\left(\chi^{2}(1)=4.70\right.$; $P<0.05)$ but did not exceed normal physiological values. We observed large interindividual differences in the effect of Ramadan on SSS: for a few persons, SSS could even decrease during Ramadan (see Figure 1). One-Way ANOVA was used to analyse possible correlations between the individual effect of Ramadan on SSS and different independent variables, but revealed no influence of age, sex, time of day, the amount of sleep in the previous night or the number of hours of fasting at the time of the test. No correlations could be detected between the amount of sleep and SSS or FAS.

Interestingly, the higher educated subjects were more tired during Ramadan, with a very limited and non-significant sleep reduction of $2 \%$ during Ramadan compared to the reference period. Within the group of lower educated subjects an opposite effect is shown: during Ramadan they were less tired compared to the reference period, despite an average 15\% sleep reduction.

\section{3. $R E A-t$}

The average reaction speed (REA- $t$ ) was $278.38 \mathrm{~ms}$ outside Ramadan, $264.57 \mathrm{~ms}$ at R1 and $263.82 \mathrm{~ms}$ at R2. Reaction speed 
was slightly better during Ramadan, but multilevel analysis showed that this effect was statistically not significant, nor was the effect of Time $\left(\chi^{2}(2)=2.80\right.$; NS). To correct for non-normality, the multilevel analysis was carried out with logtransformed REA-t.

\subsection{Rea-sd}

Multilevel analysis showed a significant effect of Ramadan on the (logtransformed) REA-sd. Log10(REA-sd) was 1.68 during Ramadan and 1.78 outside Ramadan. REA-sd decreased with around $12 \mathrm{~ms}$ during Ramadan for an average person $\left(\chi^{2}(1)=7.31 ; P<0.01\right)$. This means that concentration improved during Ramadan; see Figure 1). Time had no effect on concentration. Average REA-sd was $64.71 \mathrm{~ms}$ at the first session, $47.26 \mathrm{~ms}$ at the second session and $54.66 \mathrm{~ms}$ at the third session. Five participants went through the test for a forth time with an average REA-sd of $72.32 \mathrm{~ms}$.

\section{5. $S D S$}

Average SDS was 14.60 s before Ramadan, 13.48s at R1, 12.68s at R2 and 10.86s after Ramadan. Multilevel analysis showed that Time significantly effected SDS: for an average person, SDS decreases with 0.12 points for each unit-increase in time $\left(\chi^{2}(1)=26.00\right.$; $P<0.001)$. Ramadan did not significantly affect SDS $\left(\chi^{2}(1)=0.53\right.$; NS). There were large interindividual differences in SDS in the reference condition (ICC - a measure indicating the percentage of variation in SDS due to the hierarchical structure in the data was equal to 87\%) (See table 2 and figure 1).

Figure 1: Predicted trends throughout time for SSS, SDS, DSB, EYE and REA-sd based on multilevel analyses
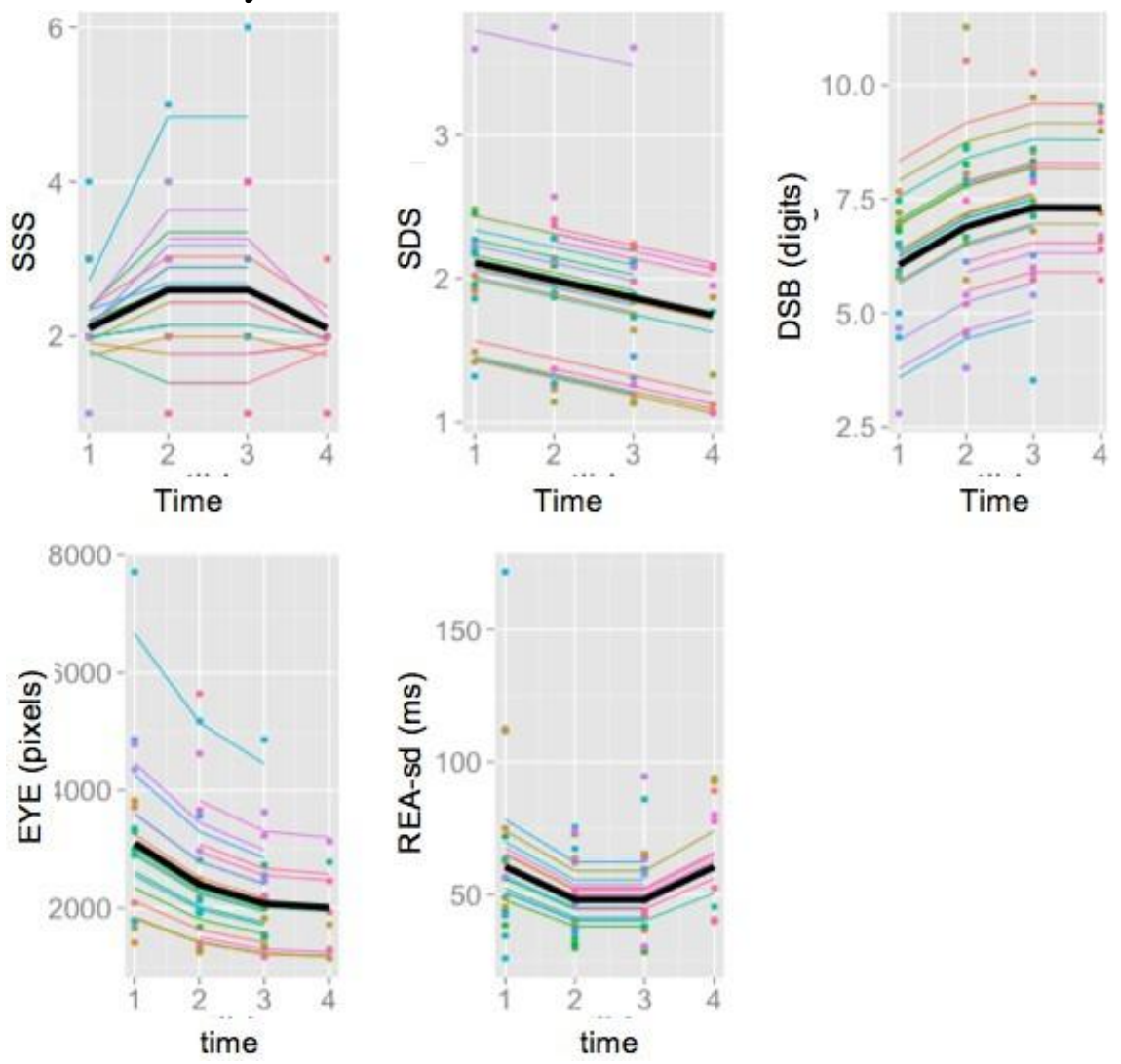
Black line: predicted trend for an average person ; coloured lines: person-specific predicted trends ; dots: observed scores for each person. For abbreviation see text, or index table

\section{6. $D S B$}

Average DSB was 6.19 digits before Ramadan, 6.91 at R1, 7.31 at R2 and 7.75 after Ramadan. Throughout time, average DSB increased with 0.47 digits per session. Multilevel analysis revealed a large significant increase of DSB per unit-increase of Time and a (small) significant increase during Ramadan $\left(\chi^{2}(2)=15.79 ; P<0.001\right)$ (See figure 1). The interaction between Time and Ramadan was not significant $\left(\chi^{2}(1)=0.003\right.$; NS). As with SDS, there were large interindividual differences in DSB at the beginning of measurement $($ ICC $=61 \%)$. (See figure 1$)$.

\section{7. $E Y E$}

Average EYE was 3340 pixels before Ramadan, 2641 at R1, 2221 at R2 and 2063 after Ramadan. Throughout time, average DSB decreased with 486 pixels per session. Multilevel analysis revealed a significant effect of Time and Ramadan on EYE: both variables lead to a decrease in EYE $\left(\chi^{2}(2)=28.46\right.$; $P<0.001$ ) (See figure 1). The interaction between Time and Ramadan was not significant $\left(\chi^{2}(1)=0.03\right.$; NS). Multilevel analysis also showed large interindividual differences in (log-transformed) EYEscores at the beginning of measurement (ICC $=61 \%$; see table 2$)$.

No correlations were found between FAS and neuroperformance parameters. Reaction times linked to SSSscores of 4 or higher were an averagely $26 \mathrm{~ms}$ longer than those linked to SSSscores within the normal physiological range. $\quad(\mathrm{F}=4.382 ; \quad P<0.05) \quad$ Other neuroperformance parameters were not correlated with SSS.

\section{DISCUSSION}

Our results confirm that Ramadan leads to reduced sleep and consequently increased moderately daytime sleepiness. Sleep reduction seemed to depend on the starting fasting hour: as fasting began very early in the morning (between 02:25h and 03:20h) most subjects skipped breakfast in $\mathrm{R} 1$, while in R2 most participants interrupted their sleep for breakfast before starting the days' fast at $04: 00 \mathrm{~h}$ or later. Our data are consistent with other studies conducted in Islamic countries reporting that Ramadan causes a shift in the sleeping pattern with a delay of both bedtime and waking up (BaHammam 2006, Roky et al 2001, Roky et al 2004).

Waterhouse et al (2008) conducted a study in 2006-2007 when Ramadan took place during autumn. They compared British Muslims to Libyan Muslims and found that during Ramadan, subjects in Libya were less active and napped more frequently in the daytime while being active after sunset. Throughout the day British Muslims were more fatigued than Libyan Muslims. As subjects in Libya had a tendency to stay inside or take airconditioned taxis when going out, the influence of climate differences is limited. Cultural differences are more likely to be a contributory factor to these differences. In western countries working hours and work activities don't change during Ramadan.

Despite the much longer fasting period in midsummer, our global results differ from the British results of Waterhouse et al (2008), as overall fatigue seemed not to be affected by Ramadan. This might be due to the fact that Ramadan in 2012 coincided with summer holidays, 
which allowed some subjects to stay in bed and maintain a normal amount of sleep instead of having to get up and go to work. However, the explanation above is not supported when we divide higher and lower educated subjects. Our findings suggest that either education level, or the corresponding job (lower educated people usually have jobs with more physical activity), might play an important role in the effect of Ramadan on fatigue. Further research is required to assess whether this difference can also be reproduced in larger study populations.

In our study, Ramadan did not impair neuroperformance parameters. There seems to be no effect on reaction time and visual perception. In contrast, attention seemed to improve significantly during Ramadan and a small beneficial effect was observed on short-term memory and hand eye coordination.

Previous studies discussing the effects of Ramadan on neuroperformance were mostly performed on students or athletes. Roky et al (2000) reported longer reaction times at day 6 of Ramadan $(P<0.05)$, but these were normalised at day 15 and day 28 (6).

Participants in the study by Tian et al (2011) had better reaction times during the second half of Ramadan $(P<0.01)$ at the identification task of the CogState test (11). Dolu et al (2007) found that concentration of medical students at the Mesulam and Weintraum Cancellation Tasks was lower during the first week Ramadan, with less targets marked and more targets missed $(P<0.01)(10)$. Lotfi et al (2010) found a significant positive effect of Ramadan, in both first and third week, on visual perception and digit span backward test in sports school students $(P<0.001)$.

Overall, these results indicate towards a negative effect on concentration and reaction time during the first week of Ramadan with a return to normal values by the second half of Ramadan, and a beneficial effect on short time memory. Findings in our study are in line with these observations, as all our measurements took place after the first week of Ramadan.

Although not anticipated, there was also an effect of time on the neuroperformance results, mainly on visual information processing and hand eye coordination. This is most likely due to learning effects, which are also documented in other studies (Tian et al 2011, Lotfi et al 2010, Doniger and Simos 2006, Halyburton et al 2007).

Halyburton et al (2007) also found a practise effect for the Digit Span Backward test, albeit significantly smaller than the time effect in our study.

Previous research by Danker-Hopfe et al (2001) indicates that SSS scores are unreliable to predict the actual state of objective sleepiness. Studies by Herscovitch and Broughton (1989) and Jewett et al (1999) showed that while sleep deprivation leads to higher SSS-scores, the effect on reaction speed and vigilance is limited.

Findings in the current study are largely concordant with these previous findings. Subjective fatigue or sleepiness is not correlated with neuroperformance parameters. The only correlation found here was that high SSS scores may lead to slower reaction time. However, as seen in figure 2, this finding might have been due to one extreme outlier. When this outlier was excluded, the correlation was no longer present. 
Figure 2: Reaction speed (REA-t) by SSS score.

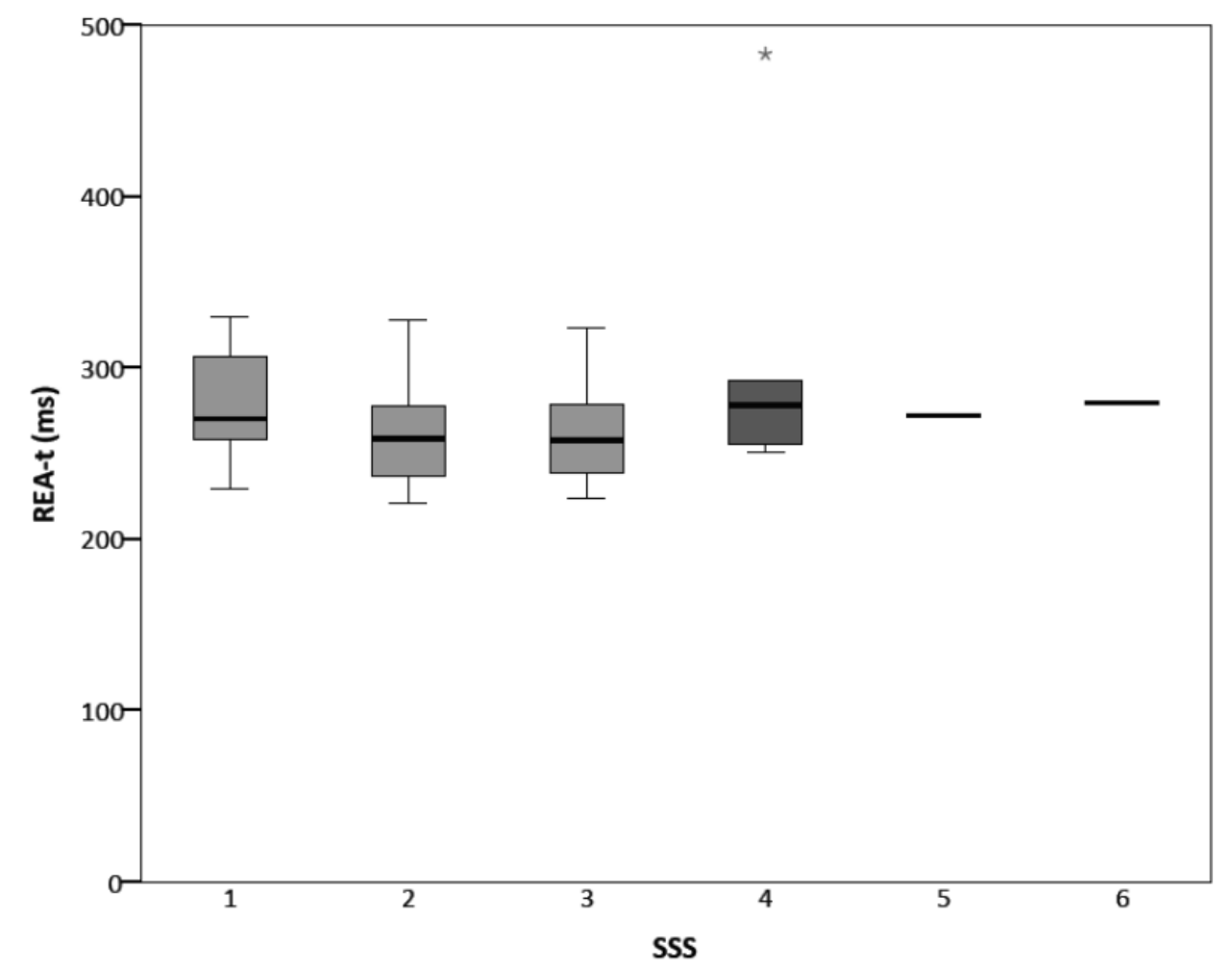

(Black line: median value; Box: interquartile distance; Whiskers: minimum and maximum values. Extreme outliers are represented by separate dots)

\section{CONCLUSION AND LIMITATIONS}

In general, the results of this study are in line with other studies performed in Islamic countries. Daytime sleepiness increases during Ramadan, but stays within the normal physiological boundaries. Neuroperformance remains mostly unaffected. On average concentration improved during Ramadan, but there are large interindividual differences. SSS or FAS scores cannot be used to predict neuroperformance results outside or during Ramadan.

In general, our results indicate that Ramadan gives employers in Western Europe no reason to withhold Muslims from jobs that require sustained attention.

Statistical significance in our study is moderate due to the small cohort size. We had to deal with big interindividual differences in the effects of Ramadan, both for fatigue and sleepiness as for neuroperformance parameters. Consequently, the lack of correlation between subjective perception of fatigue or sleepiness and neuroperformance parameters could be real or due to the small sample size. Larger studies with more power will be needed to generate more accurate results and higher statistical significance. 


\section{REFERENCES}

BaHammam A. 2005. "Assessment of sleep patterns, daytime sleepiness and chronotype during Ramadan in non-fasting individuals." Saudi Med J 26:616-622.

BaHammam A. 2006. "Does Ramadan fasting affect sleep?" Int J Clin Pract 60:1631-1637.

BaHammam A, Alrajeh M, Albabtain M, Bahammam S, Shariff M. 2010. "Circadian Pattern of Sleep, Energy Expenditure, and Body Temperature of Young Healthy Men during the Intermittent Fasting of Ramadan." Appetite 54:426-429.

Bultereys S, Viaene MK. 1994. "The Development of a Screening Test for the Neuropsychological Evaluation of Solvent-Exposed Workers." Paper presented at the 5th International Symposium on Neurobehavioral Methods and Effects in Occupational and Environmental Health, Cairo, December 37.

Danker-Hopfe H, Kraemer S, Dorn H, Schmidt A, Ehlert I, Herrman WM. 2001. "Time-of-Day Variations in Different Measures of Sleepiness (MSLT, Pupillography and SSS) and their Interrelations." Psychophysiology 38:828835.

Dolu N, Yüksek A, Sizer A, Alay M. 2007. "Arousal and Continuous Attention during Ramadan Intermittent Fasting." Journal of Basic \& Clinical Physiology \& Pharmacology 18:315- 322.

Doniger GM, Simos ES. 2006.
"Comprehensive

Computerizes

Assessment of Cognitive Sequellae of a Complete 12-16 Hour Fast." Behavioural Neuroscience 120:804-816.

Godderis L, Maertens N, de Gelder $\mathrm{V}$, De Lamper A, De Ruyck K, Vernimmen M, Bulterys S, Moens G, Thierens H, Viaene MK. 2010. "Genetic susceptibility in solvent induced neurobehavioral effects." Neurotox Res 17:268-78. doi:10.1007/s12640-009-91007.

Halyburton AK, Brinkworth GD, Wilson CJ, Noakes M, Buckley JD, Kogh JB, Clifton PM. 2007. "Low and HighCarbohydrate Weight-loss Diets have Similar Effects on Mood but not Cognitive Performance.” Am J Clin Nutr 86:580-587.

Herscovitch J, Broughton R. 1981. "Sensitivity of the Stanford Sleepiness Scale to the Effects of Cumulative Partial Sleep Deprivation and Recovery Oversleeping." Sleep 4:83-92.

Hoddes E, Zarcone V, Smythe H, Phillips R, Dement WC. 1973. "Quantification of sleepiness: a new approach." Psychophysiology 10:431-437.

Jewett ME, Dijk DJ, Kronauer RE, Dinges DF. 1999. "Dose-response Relationship between Sleep Duration and Human Psychomotor Vigilance and Subjective Alertness." Sleep 22:171-178.

Lotfi S, Madani M, Tazi A, Boumahmaza M, Talbi M. 2010. "Variation des Fonctions Cognitives et de la Glycémie lors de l'Exercice Physique durant le Jeûne du Mois de Ramadan." Revue Neurologique 166:721-726. 
Michielsen HJ, De Vries J, Van Heck GL, Van de Vijver FJR, Sijtsma K. 2004. "Examination of the dimensionality of fatigue: The Construction of the Fatigue Assessment Scale (FAS)." Eur J Psy Assess 20:39-48. doi:10.1027/10155759.20.1.39

Roky R, Chapotot F, Denchekoun MT, Benaji B, Hakkou F, Elkhalifi H, Buguet A. 2003. "Daytime Sleepiness during Ramadan Intermittent Fasting: Polysomnographic and Quantitative Waking EEG Study." J Sleep Res 12:95101.

Roky R, Chapotot F, Hakkou F, Benchekroun MT, Buguet A. 2001. "Sleep during Ramadan Intermittent Fasting. " $J$ Sleep Res 10:319-327.

Roky R, Houti I, Moussamih S, Qotbi S, Aadil N. 2004. "Physiological and Chronobiological Changes during Ramadan Intermittent Fasting." Ann Nutr Metab 48:296-303.

Roky R, Iraki L, HajKhlifa R, Ghazal NL, Hakkou F. 2000. "Daytime alertness, Mood, Psychomotor Performances, and Oral Temperature during Ramadan Intermittent Fasting." Ann Nutr Metab 44:101-107.

Tian H, Aziz AR, Png W, Wahid MF, Yeo D, Png AC. 2011. "Effects of Fasting During Ramadan Month on Cognitive Function in Muslim Athletes." Asian J Sports Med 2:145-153.

Waterhouse J, Alkib L, Reilly T. 2008. "Effects of Ramadan upon Fluid and Food Intake, Fatigue, and Physical, Mental, and Social Activities: a
Comparison between the UK and Libya." Chronobiology International 25:697-724.

Zerguini Y, Dvorak J, Maughan RJ, Leiper JB, Bartagi Z, Kirkendall DT, AlRiyami M, Junge A. 2008. "Influence of Ramadan Fasting on Physiological and Performance Variables in Football Players: Summary of the F-MARC 2006 Ramadan Fasting Study." J Sports Sciences 26 suppl.3:S3-S6.

Ziaee V, Razaei M, Ahmadinejad Z, Shaikg H, Yousefi R, Yarmohammadi L, Bozorgi F, Behjati MJ. 2006. "The Changes of Metabolic Profile and Weight during Ramadan Fasting." Singapore Med J 47:409-41 